\title{
Multiple response optimization of the effect of thyme essential oil against Listeria monocytogenes in ground meat at different times and temperatures
}

\author{
FATIH TORNUK, MUSTAFA TAHSIN YILMAZ, ISMET OZTURK* , OSMAN SAGDIC, \\ MUHAMMET ARICI, MUHAMMED ZEKI DURAK, MUSTAFA BAYRAM** \\ Food Engineering Department, Chemical and Metallurgical Engineering Faculty, \\ Yıldız Technical University, 34210, Istanbul, Turkey \\ *Food Engineering Department, Engineering Faculty, Erciyes University, 38039, Kayseri, Turkey \\ ** Mathematical Engineering Department, Chemical and Metallurgical Engineering Faculty, \\ Yıldız Technical University, 34210, Istanbul, Turkey
}

Tornuk F., Yilmaz M. T., Ozturk I., Sagdic O., Arici M., Durak M. Z., Bayram M. Multiple response optimization of the effect of thyme essential oil against Listeria monocytogenes in ground meat at different times and temperatures

\section{Summary}

Response surface methodology was used to optimize conditions (e.g., Thyme oil concentration [0.0-0.57\%] and storage temperature $\left.\left[0.0-14.14^{\circ} \mathrm{C}\right]\right)$ for inhibiting the growth of $\mathrm{L}$. monocytogenes $(\log \mathrm{cfu} / \mathrm{g})$ in ground meat. Additionally, the effect of the variables; namely, temperature and concentration on $\mu_{\text {max }}$ (maximum specific growth rate, $\mathrm{In} \mathbf{c f u} / \mathrm{g} / \mathrm{h}$ ) values was also evaluated using a proposed combined model. The best fitting second order polynomial models were developed for each response using multiple linear regression analysis with backward elimination regression (BER) procedure. In this paper, multi-response surfaces using desirability function approaches were successfully applied to determine optimum operating conditions. Under these optimum treatment and storage parameters, L. monocytogenes populations at hours 6, 24, 48, 72 and 96 were $6.12,5.96,5.88,5.81$ and $5.41 \mathrm{log} \mathrm{cfu} / \mathrm{g}$ and $0.001 \mathrm{ln} \mathrm{cfu} / \mathrm{g} / \mathrm{h}$, respectively and $\mu_{\max } v a l u e ~ 0.001 \mathrm{ln} \mathrm{cfu} / \mathrm{g} / \mathrm{h}$. At the end, the proposed combined model is described numerically and experimentally.

Keywords: Baranyi model, central composite design, Listeria monocytogenes, ground meat, thyme essential oil

The presence of L. monocytogenes is unacceptable in ground beef; therefore, it should be inactivated/ decontaminated in such meat products. In this respect, there are a great number of studies focused on reduction of the number of $L$. monocytogenes with essential oil applications. The utilization from antimicrobial activity of essential oils and extracts of many plant species have recently become popular for many pharmaceutical and food processing applications (11). Essential oil treatment is one of the effective methods for elimination of L. monocytogenes from food products (40). In the literature, there are a number of references highlighting the inhibitory effect of Thymus vulgaris on L. monocytogenes growth $(14,33,36)$.

Response surface methodology (RSM) is a useful statistical tool, allowing to improve and optimize processing conditions by finding the experimental relationship between input and output variables that are considered in an experimental design (20). Using an RSM design of experiment, it is possible to determine the relationship between the response and the independent parameters; to develop first- or secondorder mathematical models of responses as a function of the parameters studied; to map a response surface over a particular region of interest and optimize the response, and to select operating conditions to achieve target specifications or customer requirements $(6,23$, 32). Like RSM, predictive microbiological models are also widely used in the modeling of food processing to eliminate the complexity of reactions and heterogeneous structure of food products. Among the predictive models used, Baranyi is known to be capable of showing a good fit for growth curves of some pathogenic bacteria, such as Bacillus spp., Brochothrix thermospacta, Clostridium spp., Escherichia coli O157:H7, Staphylococcus spp., Yersinia enterocolitica and Salmonella Typhimurium as well as Listeria monocytogenes under different conditions $(2,4,16,38,45)$. 
Accurate assessments of Listeria growth inhibition, to a large extent, relies on technical expertise and experience that are necessary to determine the simultaneous effects of multiple factors, as opposed to conclusions based on a single factor. However, in the literature, a considerable number of studies based on RSM have been conducted using an approach with a single-response problem; conversely, limited attention has been paid to multi-response problems. Previous studies have indicated that the optimal factor settings for one response characteristic may not necessarily be compatible with those of the other response characteristics. In this respect, one of the most efficient ways to obtain desirable results is to use an appropriate statistical tool, allowing optimization of the levels of process variables. This necessitates a detailed experimental design to establish the most appropriate levels of essential oil and storage temperature to maximize growth inhibition of L. monocytogenes.

In order to achieve the best inactivation conditions, a multiple-response optimization study should be conducted, aiming to determine growth/inactivation kinetics of the bacterium in a model food system; for example, ground meat under optimum treatment and storage parameters. However, to the best of our knowledge, it seems that determination and optimization of simultaneous effects of essential oil concentration and storage temperature on the growth of $L$. monocytogenes by RSM based on the Baranyi model have heretofore not been reported. Therefore, this study was aimed to characterize and model the growth/survival of L. monocytogenes at different storage times in ground beef in order to establish optimum operating conditions. RSM and Baranyi model were used for modeling and optimization procedures.

\section{Material and methods}

Beef used in microbiological analysis was aseptically obtained from a commercial abattoir in Kayseri, Turkey. Beef including $10 \%$ to $12 \%$ fat was excised from loin muscle (cattle) of the carcasses kept in chilling room at $0 \pm 1^{\circ} \mathrm{C}$ until reaching $24 \mathrm{~h}$ of postmortem. Next, the meat was immediately transferred to the laboratory under cold chain conditions, then ground aseptically through a previously autoclaved grinder (Tefal, China).

Dried thyme $(500 \mathrm{~g})$ (Thymus vulgaris L.) identified by the scientists of botany in Erciyes University in Kayseri, Turkey were obtained from a local retail spice market. The essential oil (EO) of the plant was extracted using Clavenger apparatus by the hydro distillation method described by Baydar et al. (5). For this aim, plant material (100 g) was cut into small pieces, placed in the distillation apparatus with $2 \mathrm{~L}$ of double distilled water and hydro distilled for $3 \mathrm{~h}$. After dried over anhydrous sodium sulphate, the oils were stored at $4^{\circ} \mathrm{C}$ until analyses.

As a test bacterium, Listeria monocytogenes ATCC 7644 was used in this study. The bacterial culture was obtained
Tab. 1. Two-factor-five-level central composite rotatable design (ccrd) atrix indicating the levels of coded and actual for two variables

\begin{tabular}{c|c|c|c|c|c|}
$\begin{array}{c}\text { Experimental } \\
\text { runs }\end{array}$ & \multicolumn{2}{|c|}{$\begin{array}{c}\text { Coded level of variables } \\
\text { Temperature } \\
\left(\mathrm{X}_{1}\right)\end{array}$} & $\begin{array}{c}\text { Concentration } \\
\left(\mathrm{X}_{2}\right)\end{array}$ & $\begin{array}{c}\text { Actual level of variables } \\
\text { Temperature } \\
\left({ }^{\circ} \mathrm{C}\right)\end{array}$ & $\begin{array}{c}\text { Concentration } \\
(\%)\end{array}$ \\
\hline \multicolumn{1}{|c|}{ Factorial points } \\
\hline 1 & 1 & 1 & 12.07 & 0.48 \\
2 & 1 & -1 & 12.07 & 0.08 \\
3 & -1 & -1 & 2.07 & 0.08 \\
4 & -1 & 1 & 2.07 & 0.48 \\
Axial points & & & & \\
5 & 0 & $+\alpha(+1.414)$ & 7.07 & 0.57 \\
6 & 0 & $-\alpha(-1.414)$ & 7.07 & 0.00 \\
7 & $+\alpha(+1.414)$ & 0 & 14.14 & 0.28 \\
8 & $-\alpha(-1.414)$ & 0 & 0.00 & 0.28 \\
Center points & & & & \\
9 & 0 & 0 & 7.07 & 0.28 \\
10 & 0 & 0 & 7.07 & 0.28 \\
\hline
\end{tabular}

from Kayseri Agriculture Control Protection Management, Turkey. At the first step, stock culture of $L$. monocytogenes ATCC 7644 was inoculated to Nutrient Broth (Merck, Germany) for obtaining fresh culture and grown at $37^{\circ} \mathrm{C}$ for $24 \mathrm{~h}$. At the second step, the fresh culture of L. monocytogenes ATCC 7644 was again inoculated and activated $\left(\sim 10^{8} \mathrm{cfu} / \mathrm{ml}\right)$ in Nutrient Broth, after a second incubation at $37^{\circ} \mathrm{C}$ for $24 \mathrm{~h}$ and finally inoculated on the ground meat samples up to a final population of $10^{6} \mathrm{cfu} / \mathrm{g}$. Such a high inoculation level was selected as being one of the most frequently studied concentrations in growth/inactivation kinetic modeling studies conducted in meat products $(8$, $9,13,34,43$ ).

After the fresh ground meat samples were confirmed for the absence of L. monocytogenes ATCC 7644 as well as the presence of any L. monocytogenes, the essential oil (EO) applications were conducted. The number of L. monocytogenes ATCC 7644 was evaluated in ten ground meat samples (Tab. 1). Preliminary experiments and the growth limits of the bacterium defined the experimental range for levels of each studied factor. In this respect, appropriate concentrations of thyme essential oil were applied by surface spraying, yielding the relevant concentrations: 0.0 , $0.08,0.28,0.48$ and $0.57 \%(\mathrm{v} / \mathrm{w})$ EO per sample (10 ground meat samples according to the second order design matrix, Tab. 1). After being packed in PVC (polyvinyl chloride film wrapping material), each inoculated sample was stored at the relevant temperature levels $(0.0,2.07,7.07,12.07$ and $14.14^{\circ} \mathrm{C}$ ), as shown in the second order design matrix (Tab. 1) prior to enumeration of the pathogen cells. All experiments were conducted in triplicate.

Twenty five grams of ground meat samples were homogenized with $225 \mathrm{ml}$ of a sterile maximum recovery solution (Merck, Darmstadt, Germany). Decimal dilutions were prepared in $9 \mathrm{ml}$ sterile maximum recovery diluent solution until $10^{7}$ dilutions. L. monocytogenes was enumerated on Oxford Listeria Selective Agar (Merck, Darmstadt, Germany) using the spread-plate method, after incubation at $37^{\circ} \mathrm{C}$ for $24 \mathrm{~h}$ (1). Typical L. monocytogenes colonies 
formed on Oxford Listeria Selective Agar were counted as colony forming units (cfu) per gram after each incubation period: hours $6,12,24,36,48,60,72,84$, and 96. Bacterial counts were expressed as $\log 10 \mathrm{cfu} / \mathrm{g}$.

The Baranyi model was used to fit the sigmoidal bacterial growth curves at constant temperature conditions (3).

$$
y(t)=y_{0}+\mu_{\max } F(t)-\frac{1}{m} \ln \left(1+\frac{\exp \left[m \mu_{\max } F(t)\right]-1}{\exp \left[m\left(y_{\max }-y_{0}\right)\right]}\right)
$$

where $F(t)=t+\frac{1}{\mu_{\max }} \ln \left[\exp (-v t)+\exp \left(-h_{0}\right)-\exp \left(-v t-h_{0}\right)\right]$ and where $y(t)=\ln (x(t))(\mathrm{cfu} / \mathrm{g})$ is the logarithm of the cell number L. monocytogenes with $x(t) ; y_{0}\left(\ln \left(x_{0}\right)\right)$; $y_{\max }=\ln \left(x_{\max }\right), x_{0}$ being the initial and $x_{\max }$ the asymptotic cell concentration, respectively; $\mu_{\max }$ the maximum specific growth rate $(\mathrm{ln} \mathrm{cfu} / \mathrm{g} / \mathrm{h}) ; m$ a curvature parameter to characterize the transition from the exponential phase; $v$ a curvature parameter to characterize the transition to the exponential phase, $h_{0}$ a dimensionless parameter quantifying the initial physiological state of the cells. From that, $\lambda(\mathrm{h})$ can be calculated as $h_{0} / \mu_{\max }$. For the curvature parameters, Baranyi (2) suggested $v=\mu_{\max }$ and $m=1$.

In response modelling, multiple linear regression analysis was used and the following second-order polynomial equation of function $x_{i}$ was fitted for each factor assessed at each experimental point:

$$
Y-\varepsilon=\beta_{0}+\sum_{i=1}^{N} \beta_{i} x_{i}+\sum_{i=1}^{N} \beta_{i i} x_{i}^{2}+\sum_{\substack{i=1 \\ K<j}} \sum_{j=i+1} \beta_{i j} x_{i} x_{j}
$$

where $Y$ is the estimated response; $\beta_{0}$ is the average value of the response at the center point of the design, $\beta_{1}, \beta_{2}$, $\beta_{12}, \beta_{11}$ and $\beta_{22}$ are linear, interaction and quadratic terms, respectively.

To develop predictive models for evaluating the effect of EO concentration and storage temperature on L. monocytogenes number $(\log \mathrm{cfu} / \mathrm{g})$ enumerated at different storage times - namely, hours $6,24,48,72$, and 96 as well as $\mu_{\max }$ values (that will be described in later sections) - a 2-factor-5-level Central Composite Rotatable Design (CCRD) with two replicates at the center point was used in this study. Each enumeration time represented a different response variable. The two factors, levels and experimental design in terms of coded and uncoded (actual values) can be seen in Table 1. The CCRD is an optimal design which allows calculation, with a minimum number of experiments, with best precision possible of the linear and quadratic effects and interactions each of the two factors chosen. This design is consisted of $2^{k}$ factorial points (coded as \pm 1 notation), augmented by $2 k$ axial points $( \pm \alpha, 0,0, \ldots, 0),(0, \pm \alpha, 0$, $\ldots, 0),(0,0, \pm \alpha, \ldots, 0), \ldots,(0,0,0, \ldots, \pm \alpha)$ that are located at a specified distance $\alpha$ from the center in each direction on each axis defined by the coded factor levels. $n_{0}$ is each center point $(0,0, \ldots, 0) . k$ is the number of factors. The relationship between coded and actual values of variables was calculated using the following equation:

$$
x_{i}=\frac{z_{i}-0.5\left(z_{i, \text { max }}+z_{i, \text { min }}\right)}{0.5\left(z_{i, \text { max }}-z_{i, \text { min }}\right)}
$$

where $z$ is the actual variable, the subscripts max and min refer to the maximum $\left(12.07^{\circ} \mathrm{C}\right.$ and $0.48 \%$, respectively) and minimum values (2.07 and $0.08 \%$, respectively) and $x$ is the coded variable. In this study, rotatability and orthogonality were selected since these properties of the design are desirable. The design is rotatable if the variance of the response is constant for all variables at a given distance from the design center $(17,21)$. The CCD is rotatable if:

$\alpha=\sqrt[4]{2^{k}}$

Orthogonality of design is requisite for the evaluation of linear, quadratic and interaction effects if they are significant, indicating that different variable effects can be estimated independently. The CCRD would be nearly orthogonal if:

$N_{0}=4 N_{\mathrm{f}}^{0.5}-2 k-2$

where $N_{\mathrm{f}}$ is the number of factorial points $\left(N_{\mathrm{f}}=2^{k}\right)(35)$.

The total number of design points in CCRD can be calculated from:

$N=2^{k}$ (factorial points) $+2 k$ (axial points $)+n_{0}$ (center points)

where $N$ is the total number of design points, $k$ is the number of factors, $n_{0}$ is the number of replicates at the center point. Thus, for this design, the total number of experimental points will be $10\left(k=2 ; n_{0}=2\right)$. Table 1 shows the CCRD used and the coordinates for $k=2$ factors.

Because it is not known what the true functional relation is between the responses and the independent variables, the first-order or second-order polynomial expressions approximated the actual response surfaces for a selected experimental region $\left(2.07-12.07^{\circ} \mathrm{C}\right.$ and $\left.0.08-0.48 \%\right)$. The general model for the case of two independent variables (temperature, ${ }^{\circ} \mathrm{C}\left(x_{1}\right)$ and concentration, $\left.\%\left(x_{2}\right)\right)$ is

$Y=f\left(x_{1}, x_{2}\right)+\varepsilon$

Then, multiple linear regression analysis was used and the following second-order polynomial equation of function $x_{\mathrm{i}}$ was fitted for each factor assessed at each experimental point.

$$
Y=\beta_{0}+\beta_{1} x_{1}+\beta_{2} x_{2}+\beta_{11} x_{1}^{2}+\beta_{22} x_{2}^{2}+\beta_{12} x_{1} x_{2}+\varepsilon
$$

where $Y$ is the estimated response (different storage times: $6^{\text {th }}, 24^{\text {th }}, 48^{\text {th }}, 72^{\text {nd }}$, and $96^{\text {th }}$ in which L. monocytogenes $(\log \mathrm{cfu} / \mathrm{g})$ was enumerated as well as $\mu_{\max }$ values $(\ln \mathrm{cfu} / \mathrm{g} / \mathrm{h})$ ); $\beta_{0}$ is the average value of the response at the center point of the design, $\beta_{1}, \beta_{2}, \beta_{12}, \beta_{11}$ and $\beta_{22}$ are linear, interaction and quadratic terms, respectively, produced for the prediction models of variables (thyme oil concentration and storage temperature).

Regarding $\mu_{\text {max }}$ values, they were calculated from the Baranyi model [Eq. (1)] and used in RSM modeling [Eq. (2)] so that the performance of RSM based on the Baranyi model could be tested. For this purpose, the $\mu_{\max }$ values were calculated in terms of nine storage (enumeration) times $\left(6^{\text {th }}, 12^{\text {th }}, 24^{\text {th }}, 36^{\text {th }}, 48^{\text {th }}, 60^{\text {th }}, 72^{\text {nd }}, 84^{\text {th }}\right.$, and $\left.96^{\text {th }}\right)$ using the Baranyi model [Eq. (1)] for each experimental run (Tab. 1). Next, a total of ten $\mu_{\text {max }}$ values were analyzed using CCRD [Eq. (2)] of RSM. In this respect, the effect of the variables; namely, temperature $(t)$ and concentration $(c)$ on $\mu_{\max }(y)$ 
values was evaluated using Eq. (9), a combined model constructed from the Eqs. (1) and (2).

$y(t)=-\frac{1}{m} \ln \left\{1+\frac{\exp \left[m \mu_{\max }\left\{t+\frac{1}{\mu_{\max }} \ln \left[\exp (-v t)+\exp \left(-h_{0}\right)-\exp \left(-v t-h_{0}\right)\right]\right\}\right]-1}{\exp \left[m\left(y_{\max }-y_{0}\right)\right]}\right\}+y_{0}$

$+\mu_{\max }\left\{t+\frac{1}{\mu_{\max }} \ln \left[\exp (-v t)+\exp \left(-h_{0}\right)-\exp \left(-v t-h_{0}\right)\right]\right\}=\beta_{0}+\beta_{1} t+\beta_{2} c+\beta_{12} t c+\beta_{11} t^{2}+\beta_{22} c^{2}$

The best fitting models were determined using multiple linear regressions with backward elimination regression (BER), where insignificant factors and interactions were removed from the models and only the variables significant at $\mathrm{P}<0.01, \mathrm{P}<0.05$ and $\mathrm{P}<0.1$ levels were selected for the model construction using BER procedure. For this procedure, let the model with all possible covariates be:

$Y=\beta_{0}+\beta_{1} X_{1}+\cdots+\beta_{r-1} X_{r-1}+\varepsilon$

Next, the following $\boldsymbol{r}-1$ tests are carried out, $H_{0 j}: \beta_{j}=0$, $j=1,2, \ldots, r-1$. The lowest partial F-test value $F_{l}$ corresponding to $H_{0 l}: \beta_{l}=0$ or t-test value $t_{l}$ is compared with the preselected significance values $F_{0}$ and $t_{0}$. At the second step, one of two possible steps (step 2a and step 2b) can be taken as:

Step 2a:

If $F_{l}<F_{0}$ or $t_{l}<t_{0}$, then $X_{l}$ can be deleted and the new original model is

$Y=\beta_{0}+\beta_{1} X_{1}+\cdots+\beta_{l-1} X_{l-1}+\beta_{l+1} X_{l+1}+\cdots+\beta_{r-1} X_{r-1}+\varepsilon$

Go back to step 1 .

Step $2 b$ :

If $F_{l}>F_{0}$ or $t_{l}>t_{0}$, the original model is the model that should be chosen.

Optimization is composed of finding of all values of the process variables involving the experimental responses. The optimum point can be determined by various ways $(37,41)$. Constructing a model, the layout of the surface contours remains the easiest method to interpret. To visualize the behavior of the phenomenon studied and choose the zone of the study, these curves are analyzed, making a better output possible (35). The established model can be written in the following matrix form:

$\hat{y}=b_{0}+x_{k}^{\mathrm{t}} b_{k}+x_{k}^{\mathrm{t}} \mathbf{B} x_{k}$

where $\hat{y}$ is the predicted response, $x_{k}^{\mathrm{t}}$ is the vector transposed of the punctual coordinates in the work domain considered, $\mathbf{B}$ is the central matrix. The matrix $\mathbf{B}$ is built as follows:

$\mathbf{B}=\left[\begin{array}{cc}b_{11} & \frac{1}{2} b_{12} \\ \frac{1}{2} b_{12} & b_{22}\end{array}\right]$

Calculation of the optimal values of the process parameters was first performed on coded units by using relation 14 and then converted to actual units by Eq. 3 .

$x_{s}=-\frac{1}{2} \mathbf{B}^{-1} b_{k}$
In RSM, optimization is the ultimate aim. Many response surface problems involve the analysis of several responses. Performing simultaneous considerations of multiple responses, an appropriate response surface model is built for each response at the first step, and then a set of operating conditions that, in some sense, optimizes all responses or at least keeps them in desired ranges is estimated (30). In this respect, some of the variables are aimed to be maximized and some to be minimized. However, a competition occurs between these responses in many cases; namely, improving one response may lead another response to deteriorate, further complicating the situation. In order to overcome this problem, several approaches have been developed. In one approach, a constrained optimization procedure is used. In the second one, the contour diagrams of the different response variables is superimposed and in the third approach, the problem of multiple responses is solved through use of a desirability function which combines all the responses into one measurement. Use of desirability functions has three advantages: (1) different scaled responses can be compared with each other, (2) different responses can be simply and quickly transformed to single measurement, and (3) it is possible to simultaneously use qualitative and quantitative responses $(12,19)$.

The operating conditions, $x$ providing the "most desirable" response values can be found by this method. In this respect, different desirability functions $d_{i}\left(Y_{i}\right)$ can be used depending on whether a particular response $Y_{i}$ is to be maximized or minimized (12). Let $L_{i}, U_{i}$ and $T_{i}$ be the lower, upper and target values, respectively, that are desired for response $Y_{i}$ with $L_{i}, U_{i}$ and $T_{i}$.

If a response is maximized, then its individual desirability function is with the exponent $s$ that determines how significant it is to hit the target value. For $s=1$, the desirability function increases linearly towards $T_{i}$ which indicates a large adequate value for the response; for $s<1$, the function is convex, and for $s>1$, the function is concave (15):

$d_{i}\left(\hat{y}_{i}\right)=\left\{\begin{array}{lr}0 & \hat{y}_{i}(x)<L_{i} \\ \left(\frac{\hat{y}_{i}(x)-L_{i}}{T_{i}-L_{i}}\right)^{s} & L_{i} \leq \hat{y}_{i}(x) \leq T_{i} \\ 1 & \hat{y}_{i}(x)>T_{i}\end{array}\right.$

If a response is to be minimized, then its individual desirability function is with $T_{i}$ which indicates a small adequate value for the response: 


$$
d_{i}\left(\hat{y}_{i}\right)=\left\{\begin{array}{lr}
1 & \hat{y}_{i}(x)<T_{i} \\
\left(\frac{\hat{y}_{i}(x)-U_{i}}{T_{i}-U_{i}}\right)^{s} & T_{i} \leq \hat{y}_{i}(x) \leq U_{i} \\
0 & \hat{y}_{i}(x)>U_{i}
\end{array}\right.
$$

Having been computed for each response variable, desirability values were combined into a single desirability index, $D$. For this purpose, each response was transformed in a dimensionless function, which is called partial desirability function, $d_{i}$, which reflects the desirable ranges for each response. The desirable ranges from zero to one (least to most desirable, respectively). The definition of the partial desirability functions allows the global desirability function $D$ to calculate the weighted geometric mean of $n$ individual desirability functions (all transformed responses) [Eq. (17)] The simultaneous objective function is a geometric mean of all transformed responses $(24,32)$ :

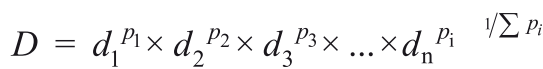

$$
\begin{aligned}
& =\left[\prod_{i=1}^{n} d_{i} p_{i}\right]^{1 / \sum p_{i}}
\end{aligned}
$$

where $p_{i}$ is the weighting of the $i_{\text {th }}$, and normalized in order that $\sum_{i=1}^{n} p_{i}=1$. By the weighting of partial desirability functions, it is possible to enable the optimization process to take the relative importance of each response into consideration. Allowing the examination of the form of the desirability function, it is possible to find the region where the function was close to 1 and determine the compromise optimum conditions. However, the overall function becomes zero in case any response or factor is outside their desirability range $(32,39)$. In the present study, the desired responses of "number of L. monocytogenes" and " $\mu_{\max }$ values" were the minimum of the target goal. The same importance was applied to each response during the optimization analysis. The modeling procedure and optimization methodology by RSM (combined the Baranyi model) is diagrammed in Fig. 1.

The computational work including designation of experimental points, randomization, analysis of variance, fitting of the second-order polynomial models and graphical representations (3D surface, studentized residual plots and desirability graphs) as well as optimization was performed using a statistical package, Design-Expert version 7.0 (Stat-Ease Inc., Minneapolis, USA). Regarding non-linear regression analysis, a non-linear regression procedure in Statistica software (Release 5.0, Statsoft Inc., Tulsa, OK, USA) was used to fit each individual set of growth data to the Baranyi model, minimizing the sum of squares of the difference between experimental data and the fitted model, i.e. loss function (observed- predicted). The Quasi-Newton algorithm option of the non-linear regression procedure was used during numerical iteration to search for the calculated parameters of each model. After several iterations in the non-linear procedure, the starting values converged to estimated values of the parameters.

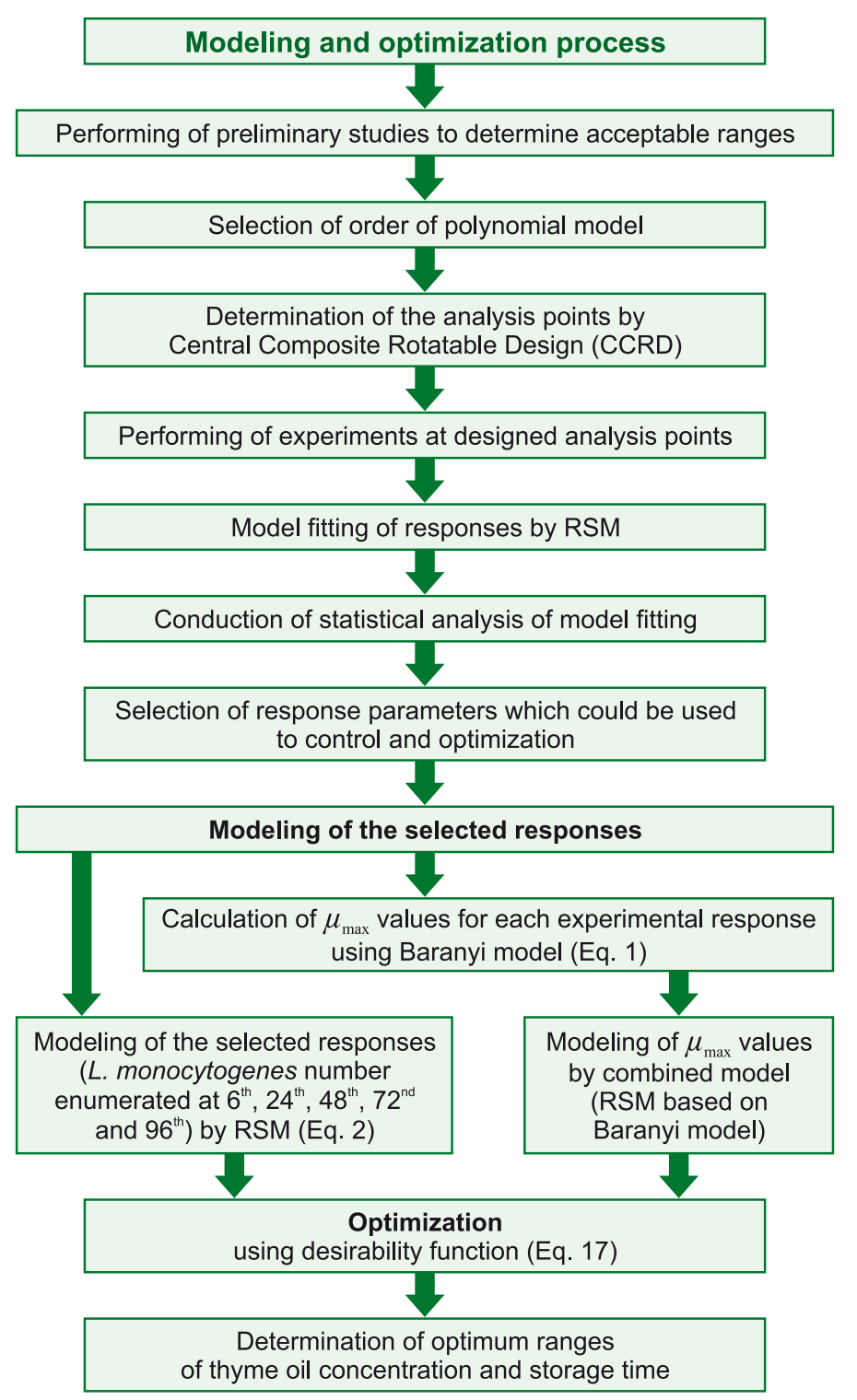

Fig. 1. Steps of modeling and optimization by RSM and a combined model (RSM based on Baranyi model)

\section{Results and discussion}

Table 1 shows the coded and uncoded levels of experimental factors. The levels of the factors were selected based on the results of preliminary experiments and limits of factors based on the literature assessments. For temperature, $14.14^{\circ} \mathrm{C}$ was the upper limit because L. monocytogenes is a psychrotropic, although it can optimally develop in the temperature range of $30^{\circ} \mathrm{C}-37^{\circ} \mathrm{C}$. In addition, ground meat is stored below $10^{\circ} \mathrm{C}$, mainly under refrigerator conditions. The lower limit of temperature was selected as $0^{\circ} \mathrm{C}$ since it can grow in a temperature range of $1^{\circ} \mathrm{C}-45^{\circ} \mathrm{C}(27,28)$. Within the studied concentration range of the thyme essential oil in this study, the lower and upper levels were selected according to the levels reported in the literature and the results of preliminary sensory analysis.

The effects of essential oil (EO) and storage temperature levels on the responses; namely, the L. monocytogenes number $(\log \mathrm{cfu} / \mathrm{g})$ enumerated at differ- 
Tab. 2. Anova table for response surface reduced linear and quadratic regression models and effects of the variables on the L. monocytogenes number $(\log \mathrm{cfu} / \mathrm{g})$ enumerated at $6^{\text {th }}$ and $24^{\text {th }}$ hours

\begin{tabular}{|c|c|c|c|c|c|c|c|c|c|c|}
\hline \multirow{2}{*}{ Source of Variance } & \multicolumn{5}{|c|}{$6^{\text {th }}$ hour } & \multicolumn{5}{|c|}{$24^{\text {th }}$ hour } \\
\hline & SS $^{\mathrm{a}}$ & $\mathrm{DF}^{\mathrm{b}}$ & MS ${ }^{\mathrm{C}}$ & $F$ value & $p$ value & SS & DF & MS & $F$ value & $p$ value \\
\hline Model & 0.41 & 1 & 0.41 & 12.20 & 0.0082 & 0.79 & 2 & 0.39 & 27.84 & 0.0005 \\
\hline$B$ (concentration) & 0.41 & 1 & 0.41 & 12.20 & 0.0082 & 0.67 & 1 & 0.67 & 47.55 & 0.0002 \\
\hline$B^{2}$ & BER $^{d}$ & & & & & 0.12 & 1 & 0.12 & 8.13 & 0.0246 \\
\hline Residual & 0.27 & 8 & 0.03 & & & 0.10 & 7 & 0.01 & & \\
\hline lack of fit & 0.27 & 7 & 0.04 & 257.8 & 0.0479 & 0.09 & 6 & 0.02 & 3.35 & 0.3954 \\
\hline pure error & $1.48 \times 10^{-4}$ & 1 & $1.48 \times 10^{-4}$ & & & $4.70 \times 10^{-3}$ & 1 & $4.70 \times 10^{-4}$ & 4 & \\
\hline total corrected & 0.67 & 9 & & & & 0.89 & 9 & & & \\
\hline$R^{2 \mathrm{e}}$ & 0.6040 & & & & & 0.8883 & & & & \\
\hline $\operatorname{adj}-R^{2 t}$ & 0.5545 & & & & & 0.8564 & & & & \\
\hline pred- $R^{2 g}$ & 0.4646 & & & & & 0.7566 & & & & \\
\hline adequate precision & 7.8110 & & & & & 12.946 & & & & \\
\hline
\end{tabular}

Explanations: a SS, sum of squares; ${ }^{\mathrm{b}} \mathrm{DF}$, degree of freedom; ${ }^{\mathrm{c}} \mathrm{MS}$, mean square; ${ }^{\mathrm{d}} \mathrm{BER}$, the reduced variable by "backward elimination regression" process; ${ }^{\mathrm{e}} R^{2}$, coefficient of determination; ${ }^{\mathrm{f}}$ adjusted $R^{2}$; g predicted $R^{2}$

Tab. 3. Anova table for response surface reduced quadratic regression models and effects of the variables on the $L$. monocytogenes number $(\log \mathrm{cfu} / \mathrm{g})$ enumerated at $48^{\text {th }}$ and $72^{\text {nd }}$ hours

\begin{tabular}{|c|c|c|c|c|c|c|c|c|c|c|}
\hline \multirow{2}{*}{ Source of Variance } & \multicolumn{5}{|c|}{$48^{\text {th }}$ hour } & \multicolumn{5}{|c|}{$72^{\text {nd }}$ hour } \\
\hline & SS $^{\mathbf{a}}$ & $\mathrm{DF}^{\mathrm{b}}$ & MS ${ }^{c}$ & $F$ value & $p$ value & SS & DF & MS & Fvalue & $p$ value \\
\hline Model & 1.05 & 3 & 0.35 & 50.76 & 0.0001 & 1.59 & 3 & 0.53 & 37.94 & 0.0003 \\
\hline $\boldsymbol{A}$ (temperature) & 0.06 & 1 & 0.06 & 8.74 & 0.0254 & 0.40 & 1 & 0.40 & 28.47 & 0.0018 \\
\hline$B$ (concentration) & 0.88 & 1 & 0.88 & 127.2 & 0.0001 & 1.05 & 1 & 1.05 & 75.03 & 0.0001 \\
\hline$B^{2}$ & 0.11 & 1 & 0.11 & 16.35 & 0.0068 & 0.14 & 1 & 0.14 & 10.32 & 0.0183 \\
\hline Residual & 0.04 & 6 & $6.93 \times 10^{-3}$ & & & 0.08 & 6 & 0.01 & & \\
\hline lack of fit & 0.04 & 5 & $8.10 \times 10^{-3}$ & 7.74 & 0.2661 & 0.08 & 5 & 0.02 & 2114.7 & 0.0165 \\
\hline pure error & $1.05 \times 10^{-3}$ & 1 & $1.05 \times 10^{-3}$ & & & $7.94 \times 10^{-6}$ & 1 & $7.94 \times 10^{-6}$ & & \\
\hline total corrected & 1.10 & 9 & & & & 1.68 & 9 & & & \\
\hline$R^{2 d}$ & 0.9621 & & & & & 0.9499 & & & & \\
\hline $\operatorname{adj}-R^{2 \mathrm{e}}$ & 0.9431 & & & & & 0.9249 & & & & \\
\hline pred- $R^{21}$ & 0.8651 & & & & & 0.8356 & & & & \\
\hline adequate precision & 19.575 & & & & & 16.819 & & & & \\
\hline
\end{tabular}

Explanations: ${ }^{\mathrm{a}} \mathrm{SS}$, sum of squares; ${ }^{\mathrm{b}} \mathrm{DF}$, degree of freedom; ${ }^{\mathrm{c}} \mathrm{MS}$, mean square; ${ }^{\mathrm{d}} R^{2}$, coefficient of determination; ${ }^{\mathrm{e}}$ adjusted $R^{2}$; ${ }^{\mathrm{f}}$ predicted $R^{2}$

Tab. 4. Anova table for response surface non-reduced and reduced quadratic regression models and effects of the variables on the $L$. monocytogenes number $(\log \mathrm{cfu} / \mathrm{g})$ enumerated at $96^{\text {th }}$ and on $\mu_{\max }$ values $(\ln \mathrm{cfu} / \mathrm{g} / \mathrm{h})^{\mathrm{a}}$

\begin{tabular}{|c|c|c|c|c|c|c|c|c|c|c|}
\hline \multirow{2}{*}{ Source of Variance } & \multicolumn{5}{|c|}{$96^{\text {th }}$ hour } & \multicolumn{5}{|c|}{$\mu_{\text {max }}$ values } \\
\hline & SS $^{b}$ & $\mathrm{DF}^{\mathrm{c}}$ & MS $^{d}$ & $F$ value & $p$ value & ss & DF & MS & $F$ value & $p$ value \\
\hline Model & 4.71 & 5 & 0.94 & 153.6 & 0.0001 & $6.59 \times 10^{-5}$ & 3 & $2.20 \times 10^{-5}$ & 76.48 & $<0.0001$ \\
\hline $\boldsymbol{A}$ (temperature) & 2.16 & 1 & 2.16 & 352.1 & $<0.0001$ & $4.36 \times 10^{-5}$ & 1 & $4.36 \times 10^{-5}$ & 152.0 & $<0.0001$ \\
\hline$B$ (concentration) & 1.09 & 1 & 1.09 & 177.0 & 0.0002 & $5.08 \times 10^{-6}$ & 1 & $5.08 \times 10^{-6}$ & 17.69 & 0.0056 \\
\hline$A B$ & 0.05 & 1 & 0.05 & 8.48 & 0.0436 & BER $^{\mathrm{e}}$ & & & & \\
\hline$A^{2}$ & 0.88 & 1 & 0.88 & 143.1 & 0.0003 & $1.71 \times 10^{-5}$ & 1 & $1.71 \times 10^{-5}$ & 59.70 & 0.0002 \\
\hline$B^{2}$ & 0.07 & 1 & 0.07 & 10.97 & 0.0296 & BER & & & & \\
\hline Residual & 0.03 & 4 & $6.14 \times 10^{-3}$ & & & $1.72 \times 10^{-6}$ & 6 & $2.87 \times 10^{-7}$ & & \\
\hline lack of fit & 0.02 & 3 & $7.79 \times 10^{-3}$ & 6.64 & 0.2762 & $1.70 \times 10^{-6}$ & 5 & $3.40 \times 10^{-7}$ & 14.98 & 0.1936 \\
\hline pure error & $1.17 \times 10^{-3}$ & 1 & $1.17 \times 10^{-3}$ & & & $2.27 \times 10^{-8}$ & 1 & $2.27 \times 10^{-8}$ & & \\
\hline total corrected & 4.74 & 9 & & & & $6.76 \times 10^{-5}$ & 9 & & & \\
\hline$R^{21}$ & 0.9948 & & & & & 0.9745 & & & & \\
\hline $\operatorname{adj}-R^{2 g}$ & 0.9883 & & & & & 0.9618 & & & & \\
\hline pred- $R^{2 \mathrm{~h}}$ & 0.9639 & & & & & 0.9260 & & & & \\
\hline adequate precision & 39.146 & & & & & 24.155 & & & & \\
\hline
\end{tabular}

Explanations: ${ }^{\mathrm{a}} \mu_{\text {max }}$, the maximum specific growth rate; ${ }^{\mathrm{b}} \mathrm{SS}$, sum of squares; ${ }^{\mathrm{c}} \mathrm{DF}$, degree of freedom; ${ }^{\mathrm{d}} \mathrm{MS}$, mean square; ${ }^{\mathrm{e}} \mathrm{BER}$, the reduced variable by "backward elimination regression" process; ${ }^{\mathrm{f}} R^{2}$, coefficient of determination; ${ }^{\mathrm{g}}$ adjusted $R^{2} ;{ }^{\mathrm{h}}$ predicted $R^{2}$ 
ent storage times; $6^{\text {th }}, 24^{\text {th }}, 48^{\text {th }}, 72^{\text {nd }}$, and $96^{\text {th }}$ are presented in Tables 2-4. Fig. 2 illustrates these effects on 3D-dimensional graphs where the direction of the effects of the variables on these properties can be seen. The second order regression model equations predicting effects of processing variables are also included
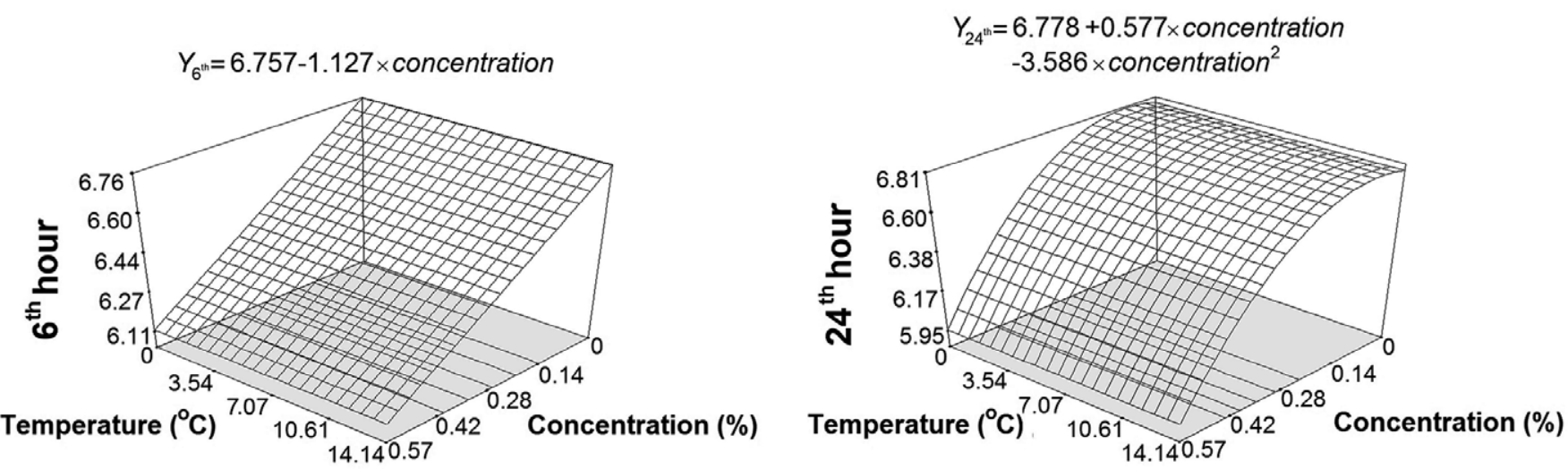

$Y_{48^{\text {th }}}=6.750+0.017 \times$ temperature $+0.352 \times$ concentration $-3.556 \times$ concentration $^{2}$

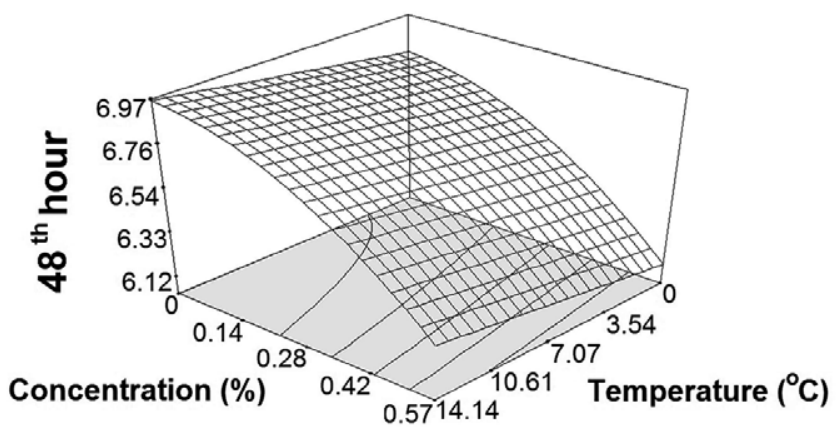

$Y_{72^{m}=6.648}+0.045 \times$ temperature $+0.460 \times$ concentration $-4.015 \times$ concentration $^{2}$

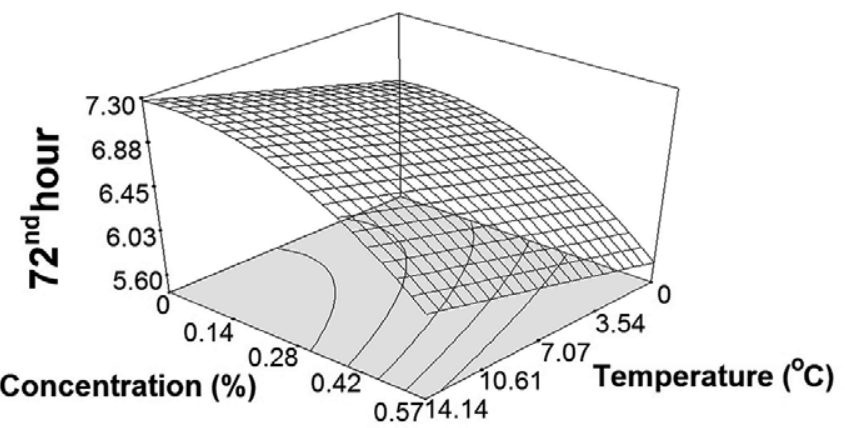

$Y_{96^{m}}=7.061-0.176 \times$ temperature $-0.933 \times$ concentration $+0.114 \times$ temperature $\times$ concentration $+0.018 \times$ temperature $^{2}$ $-3.035 \times$ concentration $^{2}$

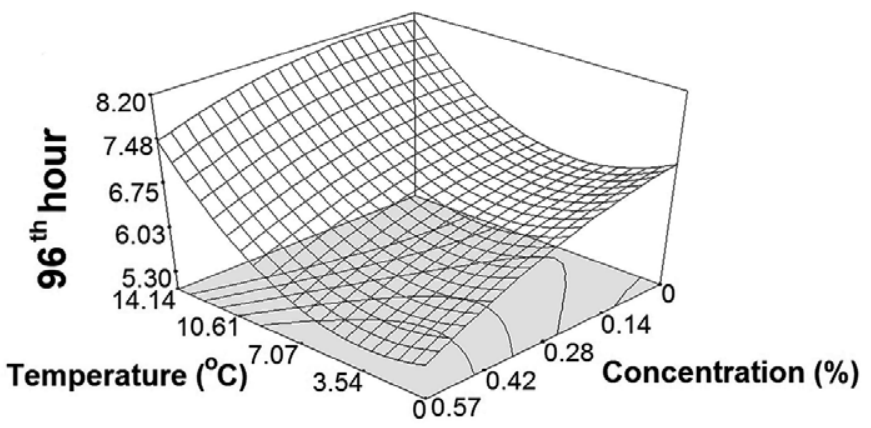

$$
\begin{aligned}
Y_{\mu_{\max }}=0.004- & 0.001 \times \text { temperature }-0.004 \times \text { concentration } \\
& +0.0001 \times \text { temperature }^{2}
\end{aligned}
$$

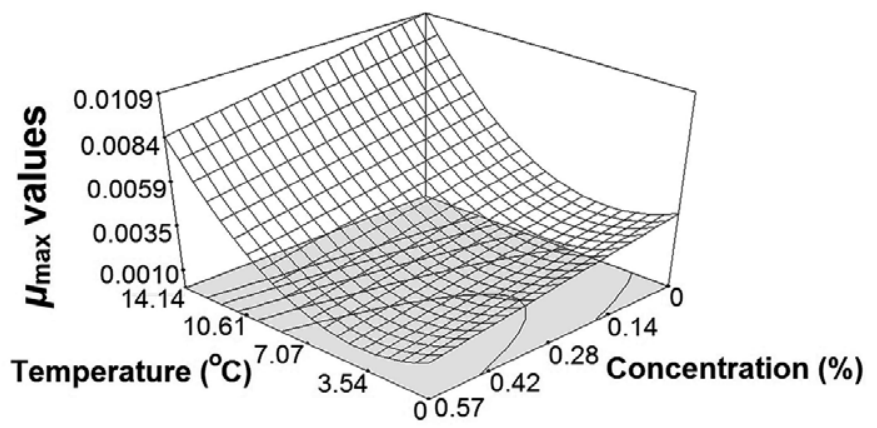

Fig. 2. Effect of temperature and concentration on $L$. monocytogenes number $(\log \mathrm{cfu} / \mathrm{g})$ enumerated at $^{6}$ th $, 24^{\text {th }}, 48^{\text {th }}, 7^{\text {nd }}$, $96^{\text {th }}$ and $\mu_{\text {max }}$ values (the maximum specific growth rate (ln cfu/g/h) evaluated using the combined model, eq. 9) along with the second-order polynomial model equations after "backward elimination regression" procedure 
in the Fig. 2. The reason why only the results for the intermediate responses $\left(6^{\text {th }}, 24^{\text {th }}, 48^{\text {th }}, 72^{\text {nd }}\right.$, and $\left.96^{\text {th }}\right)$ was analyzed using RSM was that a similar trend was also seen in the other responses $\left(12^{\text {th }}, 36^{\text {th }}, 60^{\text {th }}\right.$, and $\left.84^{\text {th }}\right)$. Results clearly revealed that linear effects of the thyme oil concentration had a significant $(\mathrm{P}<0.01$; 0.05 ) effect on the $L$. monocytogenes number enumerated at each storage time (Tab. 2-4). The number was remarkably decreased with thyme oil concentration at each storage time (Fig. 2), which indicated that thyme oil could delay the growth of $L$. monocytogenes irrespective of the storage temperature. Such a delay in microbial growth is particularly useful for food safety, which suggested that use of thyme oils could be recommended in short-term storage of products.

RSM was used to determine the optimum treatment and storage conditions of the number of L. monocytogenes and the calculated $\mu_{\max }$ values, which is achievable within the range of the tested storage times. Although the desired responses of "L. monocytogenes number" and "the $\mu_{\max }$ values" were the minimum of the target goal, the levels of the independent variables that maximize these responses were also presented in this study, as knowing the best growth conditions of
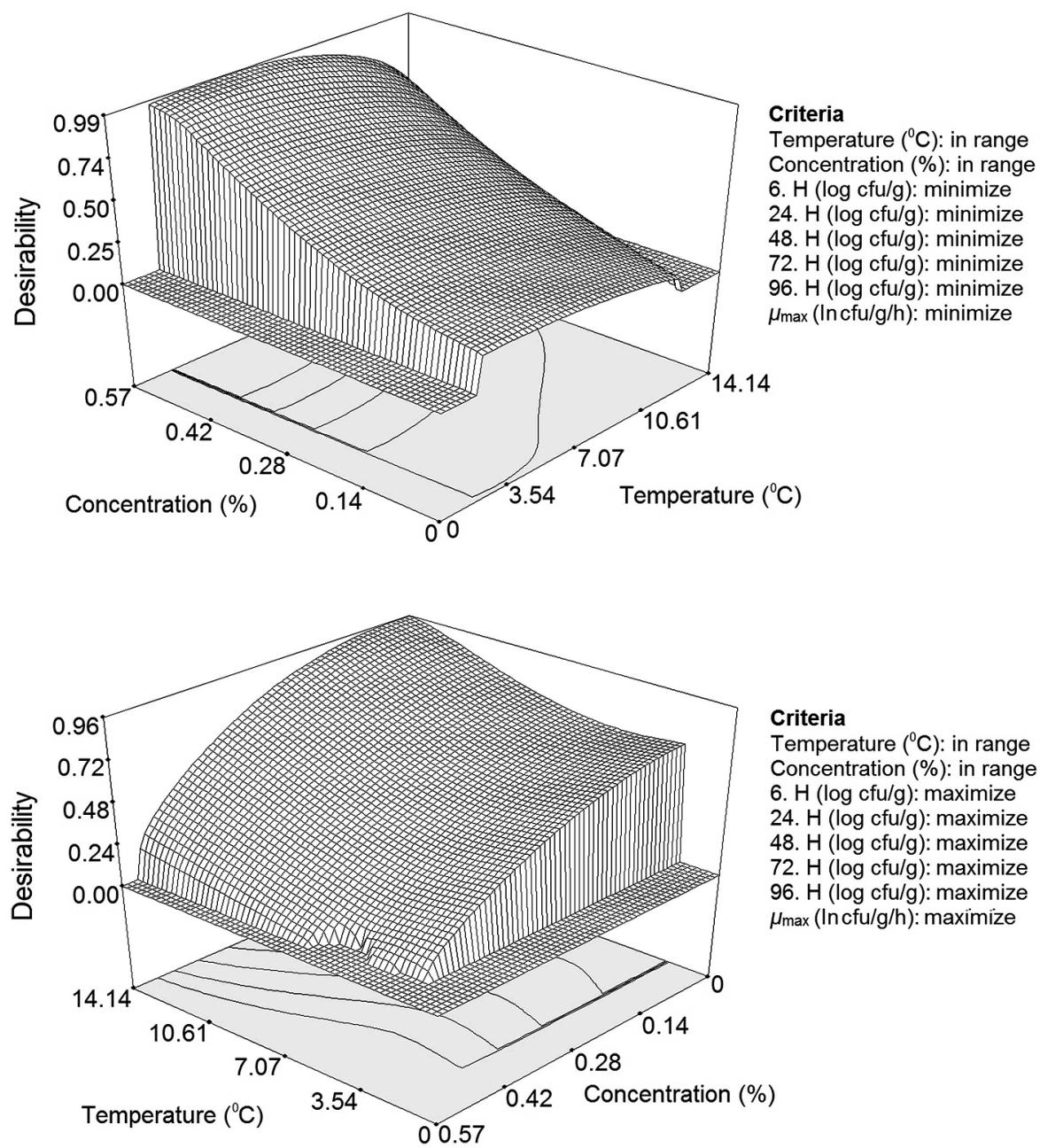

Fig. 3. Desirability function response surface for the $L$. monocytogenes number (log cfu/g) enumerated at $6^{\text {th }}, 24^{\text {th }}, 48^{\text {th }}, 72^{\text {nd }}, 96^{\text {th }}$ and $\mu_{\text {max }}$ values (the maximum specific growth rate, $\ln \mathrm{cfu} / \mathrm{g} / \mathrm{h}$ ) the bacterium with respect to the variables is also very important.

For the optimization process, desirability functions of RSM were used. The resultant optimum operating conditions with the minimization and maximization of the number of L. monocytogenes and $\mu_{\max }$ values, the criteria in these optimizations and desirability response surfaces are shown in Fig. 3. The desirability values $(D)$ for the minimization and maximization were calculated to be 0.99 and 0.96 respectively, indicating that any response or factor was inside their desirability range.

By applying the desirability function method, six solutions were obtained for each optimization process (minimization and maximization) covering the criteria; however, the most desirable solutions were presented in this study. Fig. 4 indicates these solutions. For the most desirable $(D=0.99)$ solution for minimization of each response variable, the temperature and concentration levels should be $4.18^{\circ} \mathrm{C}$ and $0.57 \%$, respectively. At this circumstance, the solution had the lowest number of L. monocytogenes $(6.12,5.96,5.88$, 5.81 and $5.40 \log \mathrm{cfu} / \mathrm{g}$ enumerated at $6^{\text {th }}, 24^{\text {th }}, 48^{\text {th }}$, $72^{\text {nd }}$ and $96^{\text {th }}$, respectively) and the lowest $\mu_{\max }$ value $(0.001 \mathrm{ln} \mathrm{cfu} / \mathrm{g} / \mathrm{h})($ Fig. 4) to get the highest product quality in terms of pathogenicity. Although the most desirable solution for maximization of the response variables was not the main goal of this study, the relevant results were also presented in this optimization study since having a knowledge on the conditions under which the number of L. monocytogenes would be the highest is also very important. For the most desirable $(D=0.99)$ solution for maximization of each response variable, the temperature and concentration levels should be $14.14^{\circ} \mathrm{C}$ and $0.02 \%$, respectively. At this point, the solution had the highest number of L. monocytogenes $(6.73,6.79,7.00,7.29$ and $8.09 \mathrm{log}$ $\mathrm{cfu} / \mathrm{g}$ enumerated at $6^{\text {th }}, 24^{\text {th }}, 48^{\text {th }}, 72^{\text {nd }}$ and $96^{\text {th }}$, respectively) and the highest $\mu_{\max }$ value $(0.011 \mathrm{ln} \mathrm{cfu} / \mathrm{g} / \mathrm{h})$ (Fig. 4) to get the lowest product quality in terms of the pathogenic load. On the other hand, it was interesting to see that there was a consistent trend between the calculated optimized response values and the storage time; namely, the minimized and maximized response values decreased and increased, respectively, as the storage time (enumeration or incubation time) increased. This indicated the antibacterial effect of thyme oil become more pronounced under the 


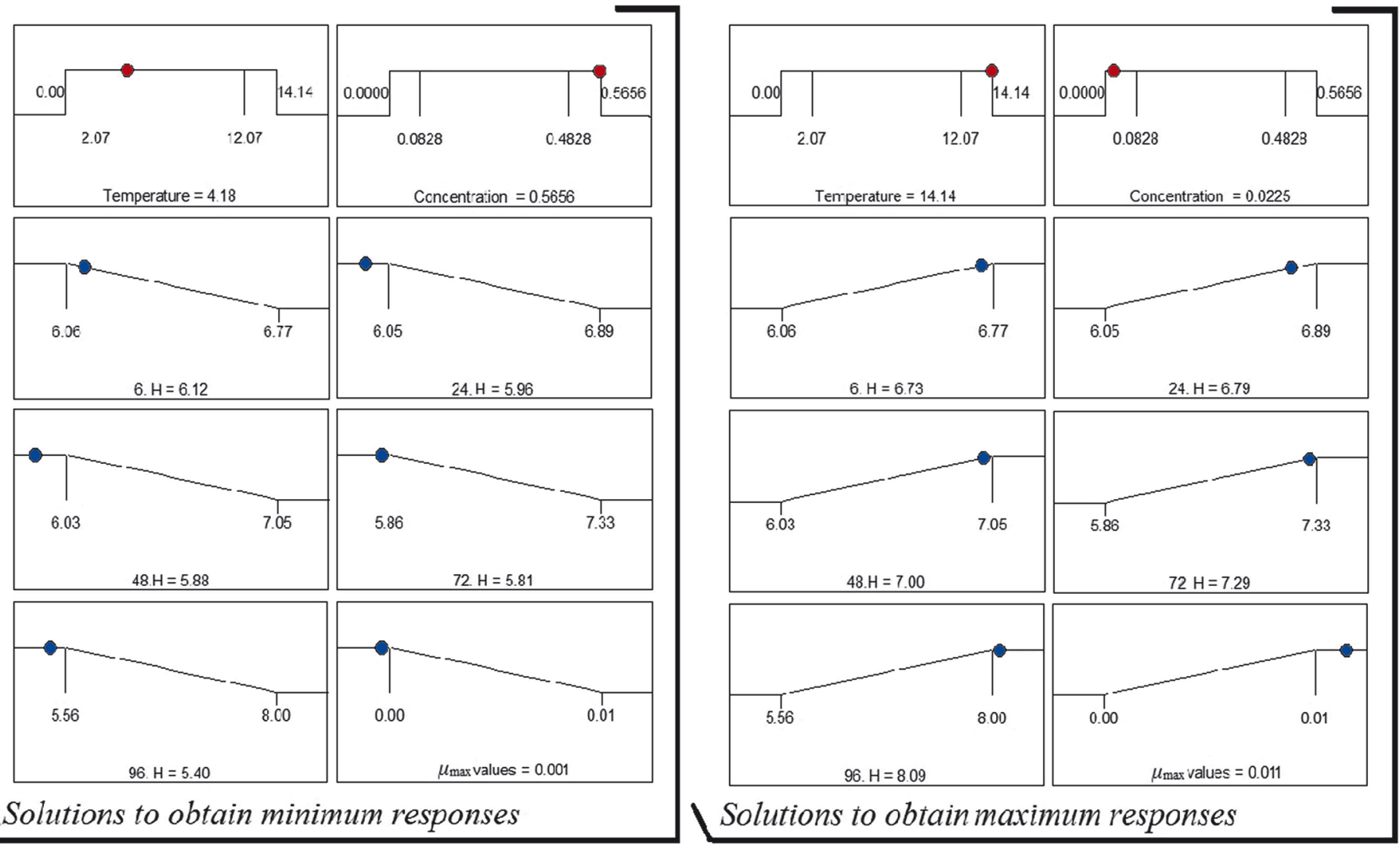

Fig. 4. Ramps reports on numerical optimization by desirability function (eq. 17) solutions for obtaining the most desirable numerical optimization by calculating the minimum and maximum response (L. monocytogenes number (log cfu/g) enumerated at $6^{\text {th }}, 24^{\text {th }}, 48^{\text {th }}, 72^{\text {nd }}$, and $96^{\text {th }}$ and $\mu_{\max }$ values $\left.(\ln \mathrm{cfu} / \mathrm{g} / \mathrm{h})\right)$ values

minimized response conditions with the prolonged storage times.

Fig. 5 indicates bar graphs which show how well each response variable satisfies the criteria. In this figure, the values close to 1 are desired. In this respect, for the minimized responses, excluding the desirability level $(D=$ 0.916) of the response (the number of $L$. monocytogenes enumerated at $6^{\text {th }} \mathrm{h}$ ), all the remaining minimized responses satisfy the criteria $(D=1)$ (Fig. 5a). Taking into account the maximized responses, there was a different case: desirability levels of only two responses (the number of L. monocytogenes enumerated at $96^{\text {th }} \mathrm{h}$ and $\mu_{\max }$ values) were 1 (Fig. 5b). These results indicated that the desirability levels of the optimized responses generally increased with extending of the storage period, which suggested that it would be better to optimize the conditions effective on growth/survival of $L$. monocytogenes within more prolonged storage time.

Effective bacteriostatic and bactericidal concentration of Thymus vulgaris on the growth of the bacterium was reported to be $1 \%(\mathrm{v} / \mathrm{v})(44)$. Hammer et al. (18)

(a)

(b)
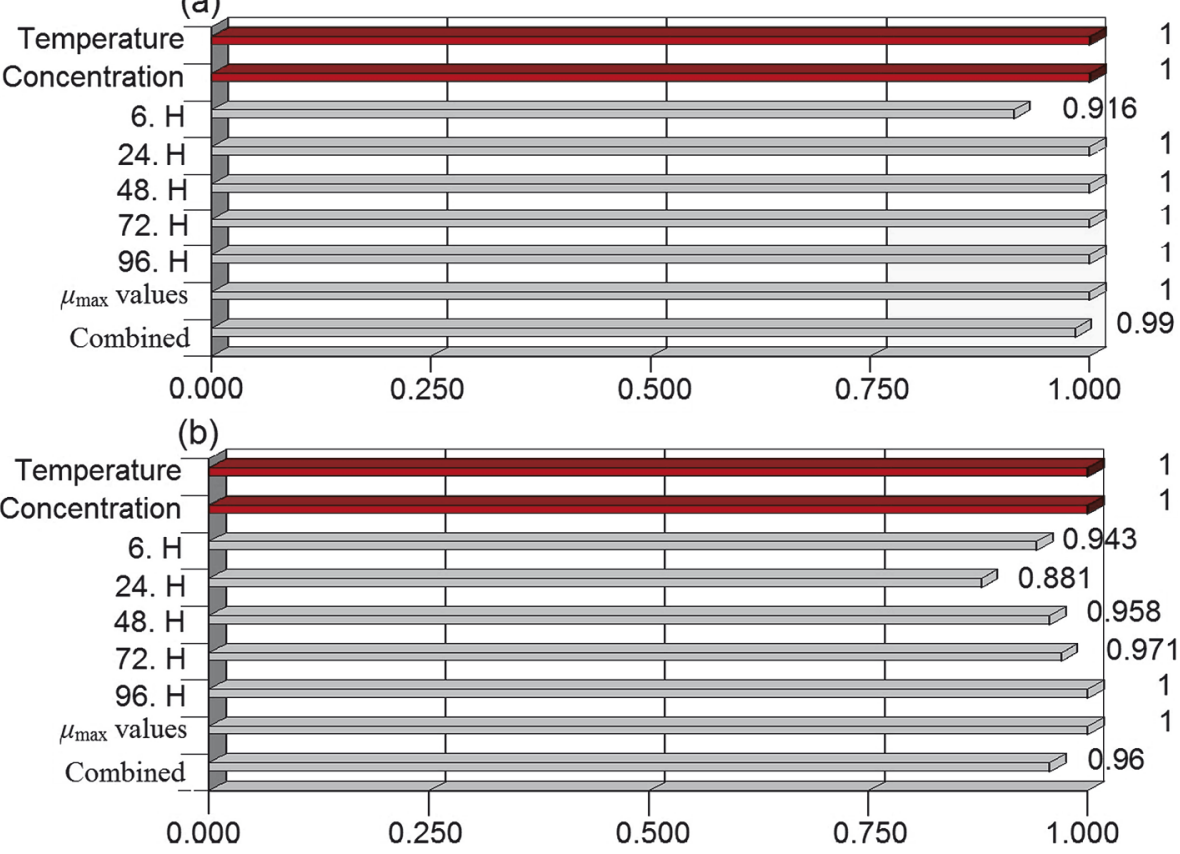

Fig. 5. Desirability level of each response (L. monocytogenes number enumerated at $6^{\text {th }}, 24^{\text {th }}, \mathbf{4 8}^{\text {th }}, \mathbf{7 2}^{\text {nd }}$, and $96^{\text {th }}$ and $\mu_{\max }$ values) after (a) minimization and (b) maximization, as calculated by desirability function (eq. 17)

reported that the concentrations of thyme oil ranging between 0.12 and $0.5 \%(\mathrm{v} / \mathrm{v})$ inhibited the bacterial growth. In addition, given the nature of CCRD design $(-\alpha$ and $+\alpha$ values in Table 1$)$, the upper limit of thyme essential oil was selected as $0.57 \%(\mathrm{v} / \mathrm{w})$ because the 
exceeded levels (more than $0.6 \% \mathrm{v} / \mathrm{w}$ ) in cooked meat were disliked by the panelists in the preliminary sensory analysis. Therefore, the lower and upper limits were selected as $0.0 \%$ and $0.57 \%(\mathrm{v} / \mathrm{w})$, respectively, to observe and determine the optimum conditions for this factor, as well as to navigate the design space. Finally, the survival/growth kinetic was monitored for a period of 6-96 h of incubation (the storage time range for the ground meat samples). This period was selected because approximately after $6 \mathrm{~h}$ of incubation the cells of $L$. monocytogenes went into an exponential phase of growth in samples with the thyme oil. After this time, the survival/growth kinetic was monitored for a period up to the extended storage time, namely, $96^{\text {th }} \mathrm{h}$ since the L. monocytogenes entered into a stationary phase of growth in different storage times and different inhibition rates were observed within a selected period of incubation depending on the different processing conditions in each experimental run (Tab. 1).

The experiments were run in a random order to minimize the effect of uncontrollable variables. Tables 2, 3 and 4 show the ANOVA results used to evaluate the significance of the constructed quadratic models. In addition, model terms were used after elimination of the insignificant ones without damaging model hierarchy and the other statistical parameters related to the adequacy of the models. The lack of fits for the models for L. monocytogenes number $(\log \mathrm{cfu} / \mathrm{g})$ enumerated at $24^{\text {th }}, 48^{\text {th }}$, and $96^{\text {th }}$ and for $\mu_{\max }$ values were insignificant $(\mathrm{P}>0.05)$, indicating that the fitted models could describe the variation of the data (7). In Tables 2 and 3, however, the models for $6^{\text {th }}$ and $72^{\text {nd }}$, the lack of fits were significant $(\mathrm{P}>0.05)$, which means that the order of the regression was not secondary; i.e., the model might have not included all appropriate functions of independent variables or the experimental region may be too large for the quadratic model used. On the other hand, it was also reported that a model with significant lack of fit could still be used when a large amount of data was included in the analysis $(6,29)$. Thus, the high coefficients $R^{2}$ have been reported to be considered as evidence of the applicability of the regression model between the ranges of variables included (29).

In this study, residual analysis, $R^{2}$ (coefficient of determination), adj- $R^{2}$ (adjusted $R^{2}$ ), pred- $R^{2}$ (predicted $R^{2}$ ) and adequate precision (adeq- -precision) values were used to check the adequacy of the models (Tab. 2-4). Fig. 6 shows the plots of studentized residuals versus the run order for the responses of models: $6^{\text {th }}, 24^{\text {th }}, 48^{\text {th }}, 72^{\text {nd }}$, and $96^{\text {th }}$ and $\mu_{\max }$ values. The plots indicate that the residuals scattered randomly, which means that the generated models were adequate (32). The $R^{2}$ and adj- $R^{2}$ values were close to each other, which showed that all terms used in the models were necessary in construction of the correct models (7). The predictive capability of the regression model is partly indicated by the pred- $R^{2}$ statistic. The pred- $R^{2}$ values were close to the adj- $R^{2}$ as expected. The $R^{2}$ values were ranged from 0.6040 to 0.9948 , indicating that majority of the models were adequate and had sufficient predicting ability. Regarding adeq-precision value implying the signal to noise ratio, a ratio greater than 4 is desired. Given this, the ratios (ranging between 7.81 and 39.15 in this study, Tables 2-4) indicate an adequate signal, which indicates that these models can be used to navigate the design space. It should be noted here that the residual analysis, $R^{2}$, adj- $R^{2}$, pred- $R^{2}$ and adeq-precision values were improved as the storage time increased.
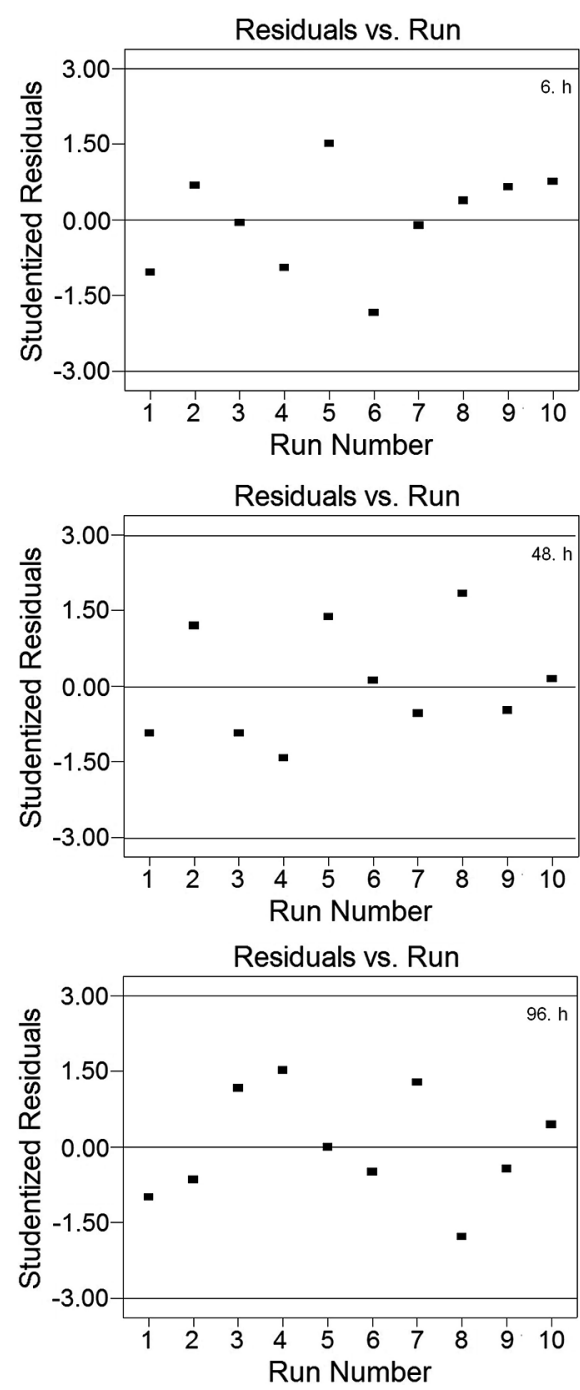

Fig. 6. Studentized residual plots for $L$. monocytogenes number enumerated at $6^{\text {th }}$, $24^{\text {th }}, 48^{\text {th }}, 72^{\text {nd }}, 96^{\text {th }}$ and $\mu_{\max }$ values (the maximum specific growth rate)
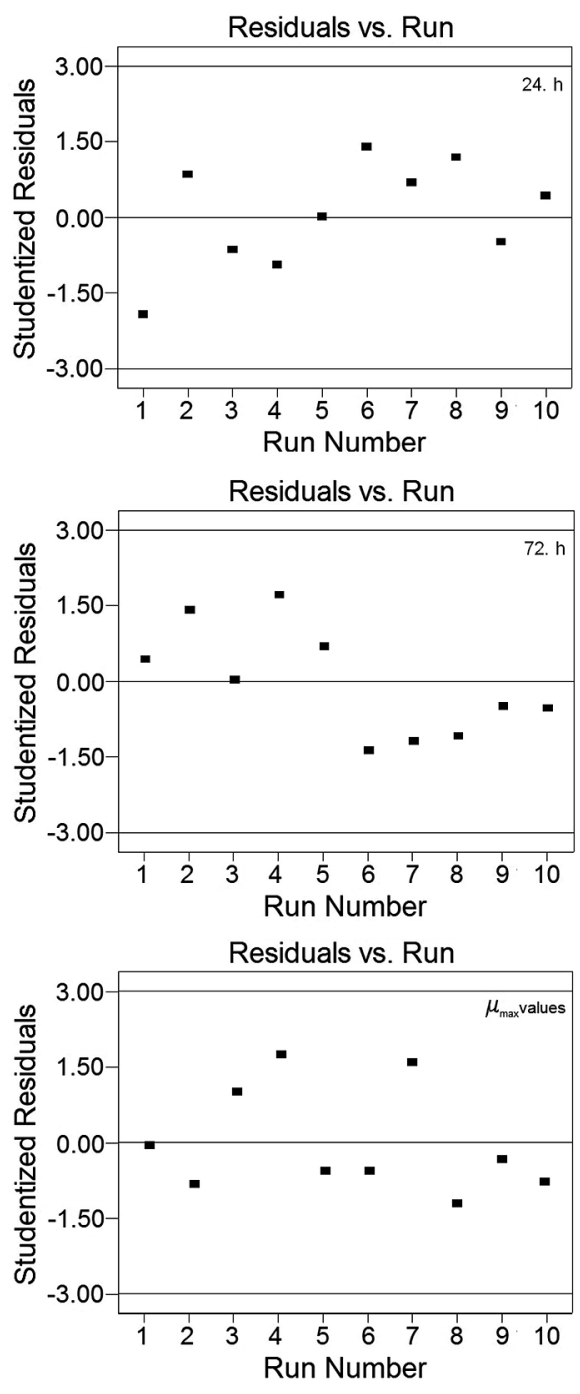

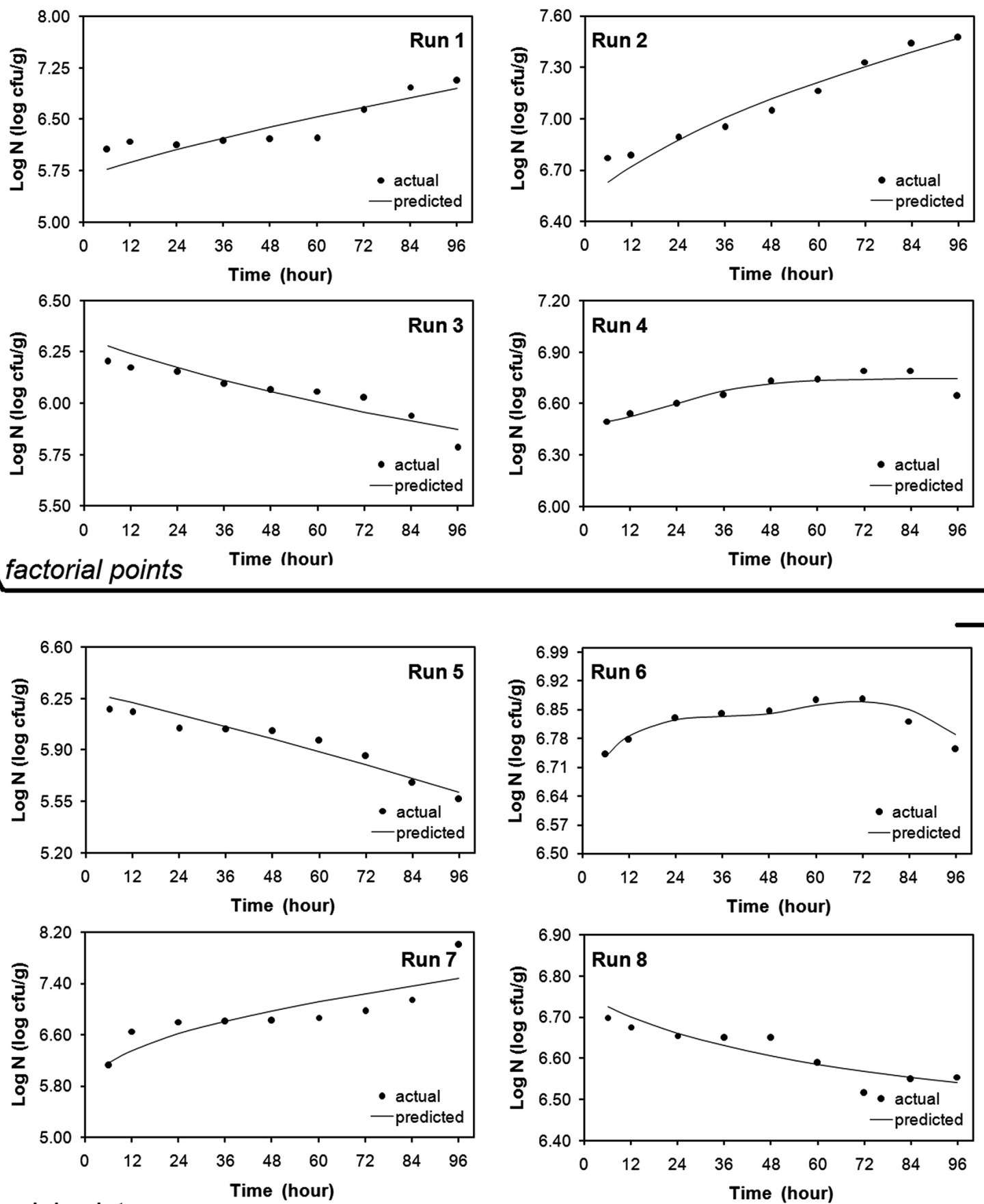

axial points
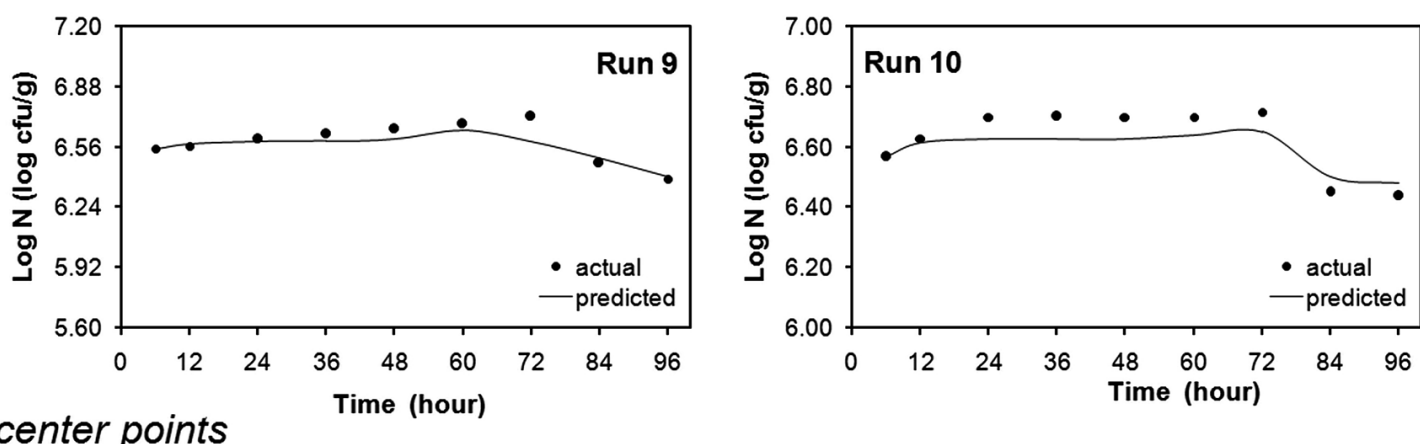

Fig. 7. Fitting of Baranyi model [eq. (1)] to experimental data (actual data) in factorial, axial and center points (table 1) for the effect of temperature and concentration on $L$. monocytogenes number $(\log \mathrm{cfu} / \mathrm{g})$ enumerated at $6^{\text {th }}, \mathbf{1 2}^{\text {th }}, \mathbf{2 4}^{\text {th }}, \mathbf{3 6}^{\text {th }}, \mathbf{4 8}^{\text {th }}$, $\mathbf{6 0}^{\text {th }}, \mathbf{7 2}^{\text {nd }}, \mathbf{8 4}^{\text {th }}$, and $96^{\text {th }}$ 
In this study, the calculated and predicted values were converted into the logarithmic unit and the values were expressed as $\log \mathrm{cfu} / \mathrm{g}$ in Fig. 7. As can be seen, the fitting of the Baranyi model to the experimental data for the effect of thyme oil concentration and storage temperature on L. monocytogenes growth in ground meat was performed for three different points; factorial points, axial points and center points. The Baranyi model was adequately fitted to each individual growth curve with $R^{2}$ values ranging from 0.84 to 0.95 .

In order to determine the optimum operating conditions that yield minimum number of $L$. monocytogenes and $\mu_{\max }$ value, RSM was used. Analysis of variance showed that the process variables - namely, thyme oil concentration and storage temperature - had significant effects on the survival of $L$. monocytogenes present in ground meat. Second order polynomial models were obtained for predicting the number of L. monocytogenes and $\mu_{\max }$ values. In addition, the $\mu_{\max }$ values calculated from the Baranyi model [Eq. 1)] could be successfully used in RSM modeling by testing the performance of RSM based on the Baranyi model.

These results are consistent with the information in literature where, in the presence of various essential oils (oregano, Origanum vulgare; rosemary, Rosmarinus officinalis and thyme, Thymus vulgaris), it was reported that food pathogen microorganisms could be inhibited $(18,44)$. This inhibition effect was attributed to the chemical composition of the tested oil. It was also reported that the phenolic compounds possess high levels of antimicrobial activity. Therefore, the antimicrobial properties of the thyme oil can be related to its high phenolic content, particularly carvacrol, thymol and $p$-cymene $(5,14,36)$. Accordingly, Sagdic and Ozturk (42) determined the EO composition of the Thymus vulgaris L. and found that carvacrol, linalool, $\delta$-carene, $\gamma$-terpinene, $o$-cymene, terpinen-4-ol and thymol were the major components with concentrations of 51.82, 4.22, 1.99, 7.68, 7.55, 2.42 and 2.14\%, respectively. Furthermore, it was also reported that the constituents of EO, such as monoterpenes (pinene, limonene and cineole), contribute to the antimicrobial effect, especially against $L$. monocytogenes, rather than the EO itself (31). Regarding the antimicrobial mechanism of these compounds, the main mechanism of action seems to be leakage of intracellular metabolites due to their activity on cell membrane, altering its functions and in some instances, causing swelling and increasing its permeability $(10,12,25)$. Penetrating into the cells, these compounds can interact with intracellular sites which cause death of the cell by modification of protein structure (22). In addition, Rasooli et al. (40) morphologically postulated that the cell wall of $L$. monocytogenes lost smoothness and uniformity as the thyme oil concentration increased; and that cell membrane disruption and lack of cytoplasm was evident at an early stage of thyme oil treatment as a result of the decrease of the cell membrane functionality as a barrier.

As for the effect of storage temperature, the growth of $L$. monocytogenes was not remarkably influenced $(\mathrm{P}>0.05)$ by storage temperature in the $6^{\text {th }}$ and $24^{\text {th }}$ of storage time (Tab. 2). However, the effect of temperature became evident $(\mathrm{P}<0.01)$ as the storage time prolonged. Accordingly, in the Fig. 2, it can be clearly seen that the number of $L$. monocytogenes decreased as the storage temperature decreased at the $48^{\text {th }}, 72^{\text {nd }}$ and $96^{\text {th }}$ of storage time, which can be expected as the bacterium can survive in a temperature range of $1^{\circ} \mathrm{C}-45^{\circ} \mathrm{C}$. At first sight, it may appear that studying the effect of temperature may not be so necessary because the effect of temperature is well-known in the literature. However, this is an optimization study and studying effect of any single variable on the pathogen growth may not be very reasonable with respect to inactivation of the pathogen in most cases. Therefore, it was important to find what the most effective combined effect of thyme oil concentration with storage temperature on the growth of the pathogen would be.

The interaction effect was significant $(\mathrm{P}<0.05)$ only at the $96^{\text {th }}$ of storage time, increasing the cell number of L. monocytogenes (Fig. 2). Finding of the most desirable combination of storage temperature with thyme oil concentration will be discussed later. Regarding quadratic effects, those of the concentration were found to be significant $(\mathrm{P}<0.01 ; 0.05)$ at $24^{\text {th }}, 48^{\text {th }}, 72^{\text {nd }}$ and $96^{\text {th }}$ and that of the temperature was found to be significant $(\mathrm{P}<0.01)$ at $96^{\text {th }}$ of storage time. From the negative signs of the regression coefficients given in Fig. 2, it can be seen that thyme oil concentration caused a further decrease in the cell numbers of L. monocytogenes after a certain concentration level at $24^{\text {th }}, 48^{\text {th }}, 72^{\text {nd }}$ and $96^{\text {th }}$. Again, from the positive sign of the regression coefficient given in Fig. 2, it is seen that the storage temperature was effective in a further increase in L. monocytogenes numbers after a certain temperature level at $96^{\text {th }}$ of storage time.

In this study, the $\mu_{\max }$ values calculated from the Baranyi model [Eq. (1)] were used for RSM modeling [Eq. (2)] so that the performance of RSM based on the Baranyi model could be tested, meaning that the $\mu_{\max }$ values were also as a response variable. As for the effect of temperature and thyme oil concentration on $\mu_{\max }$ values evaluated using the combined model [Eq. (9)], the same trend seen in the $24^{\text {th }} 48^{\text {th }}$, $72^{\text {nd }}$ and $96^{\text {th }}$ of storage time was also observed in the $\mu_{\max }$ values. Namely, the $\mu_{\max }$ values were significantly $(P<0.01)$ decreased with thyme oil concentration, but increased $(\mathrm{P}<0.01)$ with the storage temperature (Tab. 4 and Fig. 2). These results revealed that the combined model [Eq. (9)] could be successfully used to analyze the effect of processing variables on the parameter calculated by the Baranyi model.

In the food industry, the presence of L. monocytogenes is not acceptable in food products. Therefore, 
finding optimum conditions for the minimum number of $L$. monocytogenes should be of utmost importance. In this study, the most desirable $(D=0.99)$ solution for minimization of each response variable corresponds to temperature of $4.18^{\circ} \mathrm{C}$ and thyme oil concentration of $0.57 \%$ in order to obtain L. monocytogenes numbers of $6.12,5.96,5.88,5.81$ and $5.41 \mathrm{log} \mathrm{cfu} / \mathrm{g}$ (enumerated at $6^{\text {th }}, 24^{\text {th }}, 48^{\text {th }}, 72^{\text {nd }}$ and $96^{\text {th }}$, respectively) and $\mu_{\max }$ value of $(0.001 \mathrm{ln} \mathrm{cfu} / \mathrm{g} / \mathrm{h})$. Given the fact that no study has appeared to be dealing with determination and optimization of the simultaneous effect of essential oil concentration and storage temperature on the growth/survival of L. monocytogenes by RSM based on the Baranyi model, the results of this study might be interesting and suggest a promising approach for obtaining the most desirable products in terms of food safety.

\section{References}

1. Akkaya L., Telli R., Sagdic O.: Growth-death kinetics of Listeria monocytogenes in strained yogurt. Int. J. Food Prop. 2009, 12, 705-712.

2. Baranyi J.: Simple is good as long as it is enough. Food Microbiol. 1997, 14, 391-394.

3. Baranyi J., Roberts T. A.: A dynamic approach to predicting bacterial growth in food. Int. J. Food Microbiol. 1994, 23, 277-294.

4. Baranyi J., Roberts T. A.: Mathematics of predictive food microbiology. Int. J. Food Microbiol. 1995, 26, 199-218.

5. Baydar H., Sagdic O., Ozkan G., Karadogan T.: Antibacterial activity and composition of essential oils from Origanum, Thymbra and Satureja species with commercial importance in Turkey. Food Control. 2004, 15, 169-172.

6. Box G. E. P., Draper N. R.: Empirical Model Building and Response Surfaces. New York, NY: John Wiley and Sons 1987.

7. Cam M., Aaby K.: Optimization of extraction of apple pomace phenolics with water by response surface methodology. J. Agr. Food Chem. 2010, 58, $9103-$ $-9111$.

8. Cardenas F. C., Giannuzzi L., Zaritzky N. E.: Mathematical modelling of microbial growth in ground beef from Argentina. Effect of lactic acid addition, temperature and packaging film. Meat Sci. 2008, 79, 509-520.

9. Chen $H$.: Temperature-assisted pressure inactivation of Listeria monocytogenes in Turkey breast meat. Int. J. Food Microbiol. 2007, 117, 55-60

10. Cristani M., D'arrigo M., Mandalari G., Castelli F., Sarpietro M. G., Micieli D., Trompetta D.: Interaction of four monoterpenes contained in essential oils with model membranes: Implications for their antibacterial activity. J. Agr. Food. Chem. 2007, 55, 6300-6308.

11. Cowan M. M.: Plant products as antimicrobial agents. Clin. Microbiol. Rev. 1999, 12, 564-582.

12. Derringer G., Suich R.: Simultaneous optimization of several response variables. J. Qual. Technol. 1980, 12, 214-219.

13. Dickson J. S., Siragusa G. R., Wray J. E.: Predicting the growth of Salmonella typhimurium on beed by using the temperature function integrated technique. Appl. Environ. Microb. 1992, 58, 3482-3487.

14.Dimitrijevic S. I., Mihajlovski K. R., Antonovic D. G., Milanovic-Stevanovic M. R., Mijin D. Z.: A study of the synergistic antilisterial effects of a sub-lethal dose of lactic acid and essential oils from Thymus vulgaris L., Rosmarinus officinalis L. and Origanum vulgare L. Food Chem. 2007, 104, 774-782.

15. Eren I., Kaymak-Ertekin F.: Optimization of osmotic dehydration of potato using response surface methodology. J. Food Eng. 2007, 79, 344-352.

16. Fujikawa H., Kai A., Morozumi S.: A new logistic model for Escherichia coli growth at constant and dynamic temperatures. Food Microbiol. 2004, 21 , 501-509.

17. Goupy J.: Plans D’expériences Pour Surface De Réponse. Paris, France: DUNOD 1999

18. Hammer K. A., Carson C. F., Riley T. V.: Antimicrobial activity of essential oils and other plant extracts. J. Appl. Microbiol. 1999, 86, 985-990.

19. Harrington E. C.: The desirability function. Ind. Qual. Control. 1965, 21, 494-498.

20. Hejazi T. H., Bashiri M., Diaz-Garcia J., Noghondarian K.: Optimization of probabilistic multiple response surfaces. Appl. Math. Model. 2012, 36, 1275-1285 .
21. Kafarov V., Sinolecka C.: Méthodes Cybernétiques Et Technologie Chimique, Moscou: Editions Mir. 1974.

22. Kawakishi S., Kaneko T.: Interactions of proteins with allyl isothiocyanate. J. Agr. Food Chem. 1987, 35, 85-88.

23. Khuri A. I., Cornell J. A.: Response Surfaces: Designs and Analyses ( $2^{\text {nd }}$ ed.) New York: Marcel Dekker Inc. 1996

24. Lewis G. A., Mathieu D., Phan-Tan-Luu R.: Pharmaceutical Experimental Design. New York: Marcel Dekker. 1999.

25. Lin C. M., Preston J. F., Wei C. I.: Antibacterial mechanism of allyl isothiocyanate. J. Food Prot. 2000, 63, 727-734.

26. Lopez S., Prieto M., Dijkstra J., Dhanoa M. S., France J.: Statistical evaluation of mathematical models for microbial growth. Int. J. Food Microbiol. 2004, 96, 289-300.

27. Lovett J.: Listeria monocytogenes, [in:] Doyle M. P. (ed.): Foodborne Bacterial Pathogens. New York, USA: Marcel Dekker 1989, p. 735

28. Martin S. E., Fisher C. W.: Listeria monocytogenes, [in:] Robinson R. K., Batt C. A., Pate P. D. (eds.): Encylopedia of Food Microbiology. San Diego, San Francisco, New York, Boston, London, Sydney, Tokyo: Academic Press 1999, p. 1228-1251

29. Martínez K. D., Pilosof A. M. R.: Relative viscoelasticity of soy protein hydrolysate and polysaccharides mixtures at cooling conditions analyzed by response surface methodology. Food Hydrocolloid. 2012, 26, 318-322.

30. Montgomery D. C.: Design and Analysis of Experiments ( $5^{\text {th }}$ ed.). London, UK: Wiley 2001

31. Mourey A., Canillac N.: Anti-Listeria monocytogenes activity of essential oils components of conifers. Food Control 2002, 13, 289-292.

32. Myers R. H., Montgomery D. C.: Response Surface Methodology. Process and Product Optimization Using Designed Experiments. New York, USA: Wiley 1995, p. 705

33. Nedorostova L., Kloucek, Kokoska L., Stolcova M., Pulkrabek J.: Antimicrobial properties of selected essential oils in vapour phase against foodborne bacteria. Food Control 2009, 20, 157-160.

34. Olmez H. K., Aran N.: Modeling the growth kinetics of Bacillus cereus as a function of temperature, $\mathrm{pH}$, sodium lactate and sodium chloride concentrations. Int. J. Food Microbiol. 2005, 98, 135-143.

35. Oughlis-Hammache F., Hamaidi-Maouche N., Aissani-Benissad F., BourouinaBacha $S$. : Central composite design for the modeling of the phenol adsorption process in a fixed-bed reactor. J. Chem. Eng. Data 2010, 55, 2489-2494.

36. Oussalah M., Caillet S., Saucier L., Lacroix M.: Inhibitory effects of selected plant essential oils on the growth of four pathogenic bacteria: E. coli O157:H7, Salmonella Typhimurium, Staphylococcus aureus and Listeria monocytogenes. Food Control 2007, 18, 414-420.

37. Ozil P.: Plans D'expériences: Méthodes de Taguchi, Fascicule I. Grenoble, France: Institut National Polytechnique 1997.

38. Pin C., Gonzalo F. G. D. G., Ordonez J. A., Baranyi J.: Analysing the lag-growth rate relationship of Yersinia enterocolitica. Int. J. Food Microbiol. 2002, 73, 197-201

39. Pizarro C., Sáenz-González C., Pérez-Del-Notario N., González-Sáiz J. M. Microwave assisted extraction combined with dispersive liquid-liquid microextraction as a sensitive sample preparation method for the determination of haloanisoles and halophenols in cork stoppers and oak barrel sawdust. Food Chem. 2012, 132, 2202-2210.

40. Rasooli I., Rezaei M. B., Allameh A.: Ultrastructural studies on antimicrobia efficacy of thyme essential oils on Listeria monocytogenes. Int. J. Infect. Dis. 2006, 10, 236-241.

41. Sado G., Sado M. C.: Les Plans D'expériences De L'expérimentation À Làssurance Qualité; Paris, France: AFNOR Technique 1991.

42. Sagdic O., Ozturk I.: Kinetic modeling of Escherichia coli O157:H7 growth in rainbow trout fillets as affected by oregano and thyme essential oils and different packing treatments. Int. J. Food Prop. 2014, 17, 371-385.

43. Sheen S., Hwang C. A., Juneja K. V.: Modeling the impact of chlorine on the behavior of Listeria monocytogenes on ready-to-eat meats. Food Microbiol. 2011, 28, 1095-1100.

44. Smith-Palmer A., Stewart J., Fyfe L.: Antimicrobial properties of plant essential oils and essences against five important food-borne pathogens. Lett. Appl. Microbiol. 1998, 26, 118-122.

45. Yilmaz M. T.: Identifiability of Baranyi model and comparison with empirical models in predicting effect of essential oils on growth of Salmonella typhimurium in rainbow trout stored under aerobic, modified atmosphere and vacuum packed conditions. Afr. J. Biotechnol. 2011, 10, 7468-7479.

Corresponding author: Yildiz Technical University, Chemical and Metallurgical Engineering Faculty, Food Engineering Department, Davutpasa Campus, 34210, Esenler, Istanbul, Turkey, Telephone: 090.212.383.45.75, Fax: 090.212.383.45.71, E-mail: mtyilmaz@yildiz.edu.tr 